\title{
The construction of bilingual teaching of optoelectronic technology
}

\author{
Yang Zhang, Enming Zhao, Fan Yang, Qingbo Li, Zheng \\ Zhu, et al.
}

Yang Zhang, Enming Zhao, Fan Yang, Qingbo Li, Zheng Zhu, Cheng Li, Peng Sun, "The construction of bilingual teaching of optoelectronic technology," Proc. SPIE 10452, 14th Conference on Education and Training in Optics and Photonics: ETOP 2017, 104525X (16 August 2017); doi: 10.1117/12.2269893

SDIE Event: 14th Conference on Education and Training in Optics and Photonics, ETOP 2017, 2017, Hangzhou, China 


\title{
The Construction of Bilingual Teaching of Optoelectronic Technology
}

\author{
Zhang Yang ${ }^{\mathrm{a}}$, Zhao Enming ${ }^{\mathrm{a}}$, Fan Yang ${ }^{\mathrm{b}}$, Li Qingbo ${ }^{\mathrm{a}}$, Zheng Zhu ${ }^{\mathrm{a}}$, Cheng Li ${ }^{\mathrm{a}}$, Sun Peng \\ ${ }^{a}$ Key Laboratory of integrated fiber optics, Ministry of education. National Demonstration Center \\ for Physical Experiment Education, Harbin Engineering University, China. \\ ${ }^{\mathrm{b}}$ School of Foreign Languages, Harbin University, 109 Zhongxing Ave, Harbin, China.
}

\begin{abstract}
This paper combines the characteristics of optoelectronic technology with that of bilingual teaching. The course pays attention to integrating theory with practice, and cultivating learners' ability. Reform and exploration have been done in the fields of teaching materials, teaching content, teaching methods, etc. The concrete content mainly includes five parts: selecting teaching materials, establishing teaching syllabus, choosing suitable teaching method, making multimedia courseware and improving the test system, which can arouse students' interest in their study and their autonomous learning ability to provide beneficial references for improving the quality of talents of optoelectronic bilingual courses.
\end{abstract}

Keywords: optoelectronic technology, cultivating ability, Bilingual Teaching, teaching method

\section{INTRODUCTION}

With the globalization and the development of construction of innovative country, our country urgently needs large numbers of high-quality versatile talents who not only have a good command of English, but are also equipped with professional knowledge. Bilingual education can effectively combine the learning of academic knowledge with language study, which is usually the follow-up course of Basic English, the intermediate link between English learning and application. Bilingual education refers to a kind of teaching that is taught by second language or a foreign language in some of the subjects ${ }^{1}$. Nowadays, English is generally adopted in bilingual education in various specialties in our country. In order to enhance the internationalization level of undergraduate teaching, many colleges and universities have increased the weight of specialty English courses. Today, Ministry of Education has already considered the development of bilingual education as an important indicator of university evaluation. Therefore, teachers should not only have abundant professional knowledge and be good at foreign language, but also follow certain teaching principles and grasp flexible teaching techniques to exert students' subjective initiatives, arouse their learning interests, and thus make them really gain something in specialty English learning ${ }^{2}$. However, since specialty English is set up relatively late, there are a lot of problems in practical specialty English teaching. Some solutions to the existing problems in teaching will be proposed and some discussions will be made combining with practical teaching work in the following part.

\section{THE CURRENT SITUATION AND CHARACTERISTICS OF SPECIALTY ENGLISH TEACHING}

On one hand, specialty English course requires students to further consolidate the basic knowledge they have learned in Basic English. On the other hand, it requires them to grasp specialized vocabulary and understand related specialized knowledge. Therefore, there is a higher requirement for students. That is to say, students should not only grasp some basic English knowledge, but also have adequate specialized knowledge. Meanwhile, it is also a requirement for teachers to grasp solid specialized knowledge and have a good oral teaching ability. Therefore, teachers need to study continually to enhance their self-quality and levels of expertise. However, according to the specialty English teaching of our university, there are still a lot of problems to solve due to the restrictions of various factors ${ }^{3}$.

\subsection{Restrictions of English teaching materials and teaching methods}

Teaching materials are the basis of teaching. Proper teaching materials are the key to guaranteeing the quality of teaching. However, the contents of current specialty English are mainly articles or popular science readings of related industry, which can not cover all the research domains of the specialty ${ }^{4}$. Moreover, in the teaching of specialty English, 
one single teaching material is not sufficient, and there is also a need for other related teaching materials as reference

books. Needed teaching materials can not be ordered in our country, or there are only expensive teaching materials of original edition without authorized photocopy textbooks; therefore, teachers have to combine their personal research directions and experiences with teaching. All the factors above hinder the regular teaching and large-scale development of bilingual education. In the universities of our country, people pay much more attention to basic college English courses, which has been established long before and whose teaching methods are comparatively mature, rather than specialty English. Each university is equipped with voice devices, including audio devices, FM equipment and corresponding language teaching laboratories for the teaching of basic college English courses, and also equipped with foreign teachers. In contrast, the treatment for specialty English is quite bad: there are not only restrictions of hardware facilities, but also the levels of teachers' teaching are uneven; and teachers usually adopt traditional teaching methods, whose means are relatively backward. All these, to some extent, influence the teaching effects of specialty English.

\subsection{Lack of teaching periods}

Nowadays, the universities of our country lack uniform teaching syllabus and teaching program of specialty English, and compared with college English, the teaching periods are quite few. However, the learning difficulty of EST (English for science and technology) are much higher then that of college English, which leads to the lack of learning interests among students. Related data suggests that only $58 \%$ of universities of our country have established specialty English ${ }^{6}$. Although there are 120 periods of specialty English regulated by The Teaching Syllabus of College English, there are usually 40 periods in practical teaching of specialty English among universities. As a optional course, specialty English is arranged at the seventh term of senior year, when, in most cases, students are either busy with the preparations for the postgraduate entrance exams or exams of civil servants, or prepare for job hunting; in addition, due to the sufficient credits and lack of pressure, students consider that there is no need to take specialty English, which is quite unfavorable for them to grasp the new knowledge of related specialized domains.

\subsection{The unbalanced state of instruction proportion}

At present, there are two basic forms of bilingual teaching in the universities of our country: one is that selecting foreign teaching materials, teachers teach the course by speaking both Chinese and English; the other is that selecting foreign teaching materials, teachers teach the course by speaking Chinese ${ }^{7}$. With the increase enrollment of universities, English levels of students of regular institutions of higher learning are quite different. At the same time, due to the pressure of CET-4 (College English Test band 4) and CET-6 (College English Test band 6), students usually lack the ability to apply English to practical usage, which leads to the increasing difficulty for specialty English teaching. How to grasp the proportion of two languages is a difficult point in bilingual teaching. Nowadays, most of the teachers of specialty English are not clear about the essence and purposes of the setting of specialty English. They themselves lack professional training of English language, and specialty English usually has the characteristics of multi-disciplinary cross, which influences and limits teachers' teaching levels. Some universities invite teachers who teach college English to teach specialty English. However, English teachers have little knowledge of optoelectronics; when teaching, they basically adopt the traditional methods, i.e. explaining in class, and lack practical links. When explaining professional articles, they simply correspond English with Chinese, which results in the fact that students can not get deeper understanding of basic concepts of many specialized vocabularies and doesn't reach the purpose of applying specialty English in practices.

\subsection{The characteristics and requirements of specialty English}

Specialty English requires students, on one hand, to further consolidate the basic knowledge they have learned in college English; on the other hand, it requires them to grasp specialized English vocabularies, understand related specialized knowledge and express specialty thoughts. Students can grasp the basic communication skills, i.e. listening, speaking, reading, writing and translating (especially listening and speaking), through the usage of English, and thus lay a solid English basis for the bilingual teaching of specialized courses and their future work. As for the requirements for teachers, specialty English firstly requires teachers to grasp superb specialized knowledge and great spoken language teaching ability. If a teacher wants to teach students knowledge of one glass of water, he should have the storage of knowledge of one pail of water ${ }^{8}$. Therefore, teachers have to study continually, improve their own qualities and professional levels. Secondly, teachers have to grasp certain teaching methods and techniques. Students don't like scripted teaching model and rigid teaching method, so teachers have to draw their attention through various forms and colorful contents to cultivate their interests. Thirdly, teachers should communicate more with students to exert their subjective initiatives in learning. Teaching is a two-way communication activity and also a communicating means of emotions. Teachers should care for students actively, use correct way to guide them, encourage them to actively take part in teaching activities, and 
try their utmost to teach students in accordance of their aptitude. In a word, the abundant professional knowledge and good scientific literacy are the guarantee of good specialty English.

\subsection{The existing problems of specialty English teaching}

Besides consolidating the basic English knowledge, the establishment of specialty English can make students apply English to explain and understand related professional knowledge, which is beneficial for them to step in the society, better communicate with peers and obtain the latest new knowledge of professional researches. However, many specialty English courses didn't acquire good teaching effects ${ }^{9}$. Many students complain about the tediousness of mere translation, show a lack of interests and even skip classes. There are problems in the following aspects: first, teachers usually pay more attention to the reading ability of professional literature and ignore the cultivation of other abilities; second, the professional knowledge taught is old-fashioned, which leads students to a lack of interests; third, the teaching methods are rigid and cannot exert students' subjective initiatives ${ }^{10}$. In classroom teaching, students expect a relatively lively form, a interesting topic and more communication with teachers, as well as learning some professional knowledge.

\section{THE TEACHING REFORM OF SPECIALTY ENGLISH IN OPTOELECTRONIC SPECIALTIES}

\subsection{Policy supports}

Firstly, the university should realize that specialty English is an essential part of advanced engineering education. Teaching Administration Department should gradually increase the cognition of the importance of the course teaching, reinforce the administration of teaching work, standardize the establishment of courses, give policy supports to the course of specialty English, and increase the teaching weight of specialty English. Increase the teaching periods of specialty English from 2 periods per week to 4 periods per week and advance specialty English to the first term of junior year or even the whole junior year if the conditions permit. In this way, students can not only enrich their professional vocabularies and improve their abilities in reading and translating professional literature, but also cultivate their abilities in listening and speaking. Focus on students' abilities in applying professional English knowledge in the second term of junior year, such as doing academic exchanges, composing scientific articles, writing English reports, etc.

As for course teachers, give policy supports to teachers when they apply for projects or opportunities for further education. Due to the different levels of ability of specialty English teachers, there are the phenomena of the disunity of teaching materials and unsteadiness of teaching syllabus, which directly influence the teaching results of specialty English ${ }^{11}$. Therefore, teachers of specialty English have to urgently make up relevant English teaching materials in accordance with their goals for major training, whose contents include professional vocabularies in accordance with the memory rules, reading materials of specialty English like articles of science and technology or product descriptions, and translated version of textbooks of related domains. Try to select original literature of Britain and America with proper difficulty, which is beneficial to exert students' learning interests. It is extremely urgent to improve the teaching levels of specialty English teachers. Teaching Administration Department of the university should adopt flexible and diverse forms to attach importance to and reinforce the cultivation of specialty English teachers. In forms of further studies or project supports, encourage specialty English teachers to study or get training in foreign well-known universities, and establish a team of high-quality specialty English teachers through various cultivation forms.

\subsection{The improvements of teaching materials and teaching methods}

Only high-quality teaching materials can guarantee high-quality teaching. Therefore, compiling original teaching materials, which are innovative and advanced, and satisfy the needs of scientific and technological development, major adjustments of universities and teaching reform, is the best choice. The compilation of teaching materials should not only consider the language but also professional contents, stress ideological level, scientificity, practicability and interestingness ${ }^{12}$. They should not only include the basic principles and important laws but also literary selections of modern science and technology and latest progress in science and technology. As for teaching methods, lay emphasis on the diversity of methods and the cultivation of students' learning interests; and change students from "ask me for study" to "I want to study". During the teaching process of specialty English, draw support from multimedia teaching, which can not only save time, but also attract students' attention. Furthermore, enrich classroom teaching contents by utilizing relevant software like Flash and videos, which is beneficial to the instruction and understanding of the latest progress in science and technology. Meanwhile, communicate with students with the help of network platforms to mobilize their positivity and subjective initiatives in and after class. 


\subsection{The improvement of course assessment mechanism}

Due to the insufficient importance the universities lay to specialty English, specialty English is always as an optional course and lacks uniform management and test, which leads the fact that the assessment form is single, students lay insufficient importance, classroom atmosphere is tedious and boring, and thus the course becomes another professional course or a translation course ${ }^{13}$. Examination evaluation is an important guarantee for realizing teaching objectives, and scientific test results can provide a good feedback with teaching to help teachers to know the teaching results. Therefore, while increasing the proportion of specialty English teaching, adopt diversified assessment forms to improve teaching quality. There should be not only paper-setting of examinations but also the measurement for students' application ability, such as group discussion, personal report, etc., which can not only enhance their learning initiatives, but also exert their learning interests, and thus reflect the teaching results objectively.

\subsection{The improvements of preparing lessons}

Preparing lessons is the primary link of teaching process. Teachers should prepare lessons from three aspects, i.e. preparing knowledge, preparing methods and preparing students. Teachers should earnestly prepare for the contents of courses, such as text knowledge, English grammar, vocabulary, etc., and reasonably design questions directing at contents of the course. Questions are the bond of two-way communication between teachers and students. Students can practice their oral expression ability during the question-answer process ${ }^{14}$. Fully prepare for the scope of questions, such as asking the meaning of a certain word in the article, asking the meaning of paragraphs in the article, the question like how to cope at certain situation, etc., for example, when doing experiments, how to measure physical quantity like light intensity? Preparing methods refers to preparing for teaching methods when preparing lessons. For example, adopt the means of lecture plus question for the first paragraph of the text, while adopt the means of self-study and discussion for the second paragraph. Preparing students means to know their levels, i.e. know fairly well to ask which student or students to answer the challenging questions. In other words, teach students in accordance of their aptitude on the basis of knowing them.

\subsection{Completing measurements in two-way communication, evaluation and incentives}

Establish reasonable incentive and praise system, i.e. when guiding the students, give them opportunities to express themselves, find their advantages, praise and encourage them more to make everyone improve oneself. In addition, make records about students' attendances. The writers used to ask students to answer questions according to the student list, but found that they only did exercises or calculation when they were asked to answer questions and ignored others because they didn't have to answer the questions. Later, random questions and recording scores lively were adopted. In this way, every student has the equal opportunity to answer questions and they don't have to prepare for the question very early ${ }^{15}$. Asking questions in class can let teachers grasp the learning level of individual student, which is beneficial to teach students in accordance of their aptitude. When asking questions next time, teachers can design questions of different difficulties according to the level of individual student, and give praises and encouragements to every student who actively answers the question.

\subsection{Extracting institutional themes and pointing out learning focuses}

At the beginning of each lesson, first recall the learned contents of courses, and introduce the main contents and focuses of this lesson, namely, make a connecting link between the preceding and the following or gain new insights through reviewing old material. Specialty English teaching materials are usually some chapters of original English articles. Besides letting students understand the contents of the article, teachers should extract and summarize the key teaching points, with the purpose to let students know clearly what they should learn in language, what they should master and to what extent during the teaching process of this lesson. For instance, how to describe the charts? How to introduce the inner structure of devices? During teaching, focus on the comprehensive cultivation of abilities in listening, speaking, reading and writing, ask students to understand and read related professional articles; meanwhile, cultivate their communicating abilities in speaking and listening, and pass on necessary writing knowledge of professional literature. After teaching, make them do corresponding exercises to practice and consolidate what they have learned ${ }^{16}$.

\subsection{Properly utilizing network and multimedia resources}

Network and multimedia resources can play a stimulative role in the teaching of specialty English. By utilizing the Internet, teachers can find out the hot issues students are interested in, and elaborately make multimedia courseware to improve students' learning results. Select proper supplementary materials for learning besides teaching texts. For example, after the successful launch of Shenzhou-10 spacecraft, the writer collected some pictures and reports of foreign 
media about Shenzhou-10 spacecraft and made a brief PPT for students. Meanwhile, asked students supplement it with stories they knew about Shenzhou-10 spacecraft, organized them to discuss it and make statements and inquired their feelings when watching the live telecast of launch of Shenzhou-10 spacecraft ${ }^{17}$. Thereby, reach the purpose of encouraging and educating students mentally as well as making them learn related professional knowledge. During this teaching process, students presented great learning interests and rising learning initiatives, and kept a great classroom discipline.

\section{CONCLUSION}

A deep understanding of specialty English teaching in universities has been gained through several years' teaching of specialty English and reform practice of related teaching methods and means. With the development of society and the advance of science and technology, there are many problems of current specialty English teaching due to various restrictions. Therefore, both teachers and Teaching Administration Department should realize the educational reform of specialty English is urgent. We should enhance the teaching quality and students' learning interests from diversity perspectives, such as improving the contents of courses and teaching models of specialty English continually, improving teachers' levels of teaching, using multiple teaching methods, improving the matching hardware facilities of specialty English, etc. Only in this way, can we furthest exert students' learning initiatives, and gradually improve their ability in specialty English to better serve the advance of technology and development of society.

\section{REFERENCES}

[1] Niu, J., Yang, Q., Cong, Y., Liu, D., Cao, B. and Zheng, J., "Construction and innovation of experimental teaching center of optoelectronics to meet demand of market," Experimental Technology and Management 28(7), 268-273(2011).

[2] Korntip Tohsing, Michael Schrempf, Stefan Riechelmann, et al. Measuring high-resolution sky luminance distributions with a CCD camera[J]. Applied optics, 2013: 1564-1567(2013).

[3] Yang, C., Liu, J. and Wang, Y., "Practice and exploration of constructing experimental teaching center of optoelectronics," Experiment Science and Technology 6(4), 165-167(2008).

[4] Ge, J., "Intensify practice education - the exploration of teaching reform in course of optoelectronics," Optical Technique 35(suppl.), 167-170 (2009).

[5] Zhou C T,Cai T X,Lai C H.Model-based detector and extraction of weak signal frequencies from chaotic data[J].Chaos,2008,18(1):1-12. (2008).

[6] O.Bernal, M. Cousineau, M. Lescure. Current-Mode Pipelined ADC for High Resolution Mono- lithic CCD Processors[C]. Instrumentation and Measurement Technology Conference, 2005, 13-18(2005).

[7] Hu, J., Xu, J., Dong, X., Zhao, J. and Zhang, Z., "The idea and practice about building photo-electronics labs," Research and Exploration in Laboratory 25(10), 1306-1308(2006).

[8] Li, L. and Liu, H., "The teaching reform and construction of practice in optoelectronics," Journal of Educational Institute of Jilin Province 30(3), 49-50(2014).

[9] Samblowski A,Vollmer C E,Baune C,et al.Weak-signal conversion from 1550 to $532 \mathrm{~nm}$ with $84 \%$ efficiency[J].Optical Letters,2014,39(10):2979-2981. (2014).

[10] Jang Wooyoung, D. Z. Pan. Application-Aware No C Design for Efficient SDRAM Access[J]. IEEE Transactions on Computer-Aided Design of Integrated Circuits and Systems, 2011, 30(10): 15211533(2011).

[11] Wang, Y., Luo, Q., Liu, J. and Cao, D., "The exploration of the continuable development of the practical teaching through setting the responsible professors," Chinese Journal of Scientific Instrument 31(8), 205209(2010).

[12]Zhao P,Li Z S.Design of the high speed data acquisition and processing system based on DSP[J].Applied Mechanics and Materials,2013,(284):3667-3671. (2013).

[13] Liu, H., Wang, J. and Li, J., "Optoelectronic technology experimental teaching reform," Valuable Project 13(suppl.), 256(2012).

[14] Tang G H,Wang J C.Sound card based digital correlation detection of weak photoelectrical signals[J].European Journal of Physics,2005,26(5):835-841. (2005). 
[15] Shi S H,Yuan Y,Wang H Q,et al.Weak signal frequency detection method based on generalized Duffing oscillator[J].Chinese Physics Letters,2011,28(4):40502-40505. (2011).

[16] Xu Y C,Qu X D,Li Z X.Frequency detection of self-adaption control based on chaotic theory[J]. Chinese Physics B,2015,24(3):206-210. (2015).

[17] Li, D. "The exploration of experimental teaching reform in optoelectronics," Science and Technology Information 15, 168(2010). 